\title{
The Effects of Teneligliptin on Lipid Profile: A Prospective Study for Comparison of Biomarkers Before and After a Meal
}

\author{
Osamu Tomonaga ${ }^{\mathrm{a}, \mathrm{c}}$, Masaki Kobayashi ${ }^{\mathrm{b}}$, Ryoma Tagawa ${ }^{\mathrm{b}}$, Yoshikazu Higami ${ }^{\mathrm{b}}$
}

\begin{abstract}
Background: In the treatment of diabetes mellitus, it is important to prevent dyslipidemia, which is one of the complications. However, no study has examined the long-term effects of teneligliptin on the blood parameters of apolipoprotein B (apoB) after a meal in patients with type 2 diabetes.
\end{abstract}

Methods: The effects of teneligliptin on blood glucose and lipids were examined by measurement of biomarkers before and after a meal. We gathered data before and after 6-month treatment in diabetic patients.

Results: After treating 31 patients with teneligliptin for 6 months, the blood level of apoB-48, expressed as total area under the curve (tAUC), was significantly decreased. A multiple regression analysis of factors affecting the decreases in apoB-48 tAUC indicated that apoB-48 is more likely to decrease if it is higher at the start of testing, and that the apoB-48 tAUC value is more likely to fall in women than in men.

Conclusions: Teneligliptin may be beneficial for the treatment of postprandial hyperlipidemia in diabetic patients.

Keywords: DPP4 inhibitors; Meal tolerance test; ApoB-48; Type 2 diabetes; Teneligliptin

\section{Introduction}

Diabetes mellitus $(\mathrm{DM})$ is one of the strongest risk factors

Manuscript submitted July 30, 2020, accepted August 5, 2020

Published online August 26, 2020

${ }^{a}$ Diabetes and Lifestyle Center, Tomonaga Clinic, Tokyo 160-0022, Japan bLaboratory of Molecular Pathology and Metabolic Disease, Faculty of Pharmaceutical Sciences, Tokyo University of Science, Chiba 278-8510, Japan ${ }^{\mathrm{c} C o r r e s p o n d i n g ~ A u t h o r: ~ O s a m u ~ T o m o n a g a, ~ D i a b e t e s ~ a n d ~ L i f e s t y l e ~ C e n t e r, ~ T o-~}$ monaga Clinic, Shinyon Curumu Building 9F, 4-2-23, Shinjuku, Shinjuku-ku, Tokyo 160-0022, Japan. Email: boss@tomonaga-clinic.com

doi: https://doi.org/10.14740/jem679 for cardiovascular events. Coexistence of dyslipidemia and diabetes elevates the incidence of cardiovascular events [16]. Seshasai et al reported that the risk of vascular death was approximately doubled in patients with diabetes and dyslipidemia compared to those without diabetes [5]. And the risk of ischemic heart disease in DM patients with low-density lipoprotein cholesterol (LDL-C) of $160 \mathrm{mg} / \mathrm{dL}$ or higher has also been reported to be 3.7 times that in those with LDL-C less than $100 \mathrm{mg} / \mathrm{dL}[7,8]$. However, it has been reported that the risk of cardiovascular events when dyslipidemia and diabetes coexist can be reduced by lowering blood sugar and lipids [9-11]. When treatment with simvastatin for major vascular events among participants with these diseases was performed, there was a definite $22 \%$ reduction in the event rate [10]. Like these reports, it is important to control blood sugar and lipids.

Dipeptidyl peptidase-4 (DPP4) inhibitors improve lipid metabolism as well as glucose metabolism in animal experiments [12-14] and human clinical trials [15-18]. Used as a lipid index, apolipoprotein B-48 (apoB-48) is an apoprotein synthesized in the small intestine and a constituent of chylomicrons, triglyceride (TG)-rich lipoproteins. Unlike apoB-100, which is mainly synthesized by the liver, apoB-48 is the most suitable biomarker for investigating postprandial chylomicron metabolism [19], and its high value is indicative of postprandial hyperlipidemia.

Postprandial hyperlipidemia is a risk factor for arteriosclerosis and cardiovascular disease $[20,21]$. It is reported that apoB-48 increment after a test meal increases small dense low-density lipoprotein cholesterol independently of TG [22]. Therefore, suppressing apoB-48 after eating is important. However, in clinical practice, blood is collected in the fasting state and as needed, and there are only a few reports using post-meal dietary load testing to more accurately grasp the effects of drugs.

Among the DPP4 inhibitors examined for effects on blood apoB-48 levels before and after lipid loading or dietary loading in type $2 \mathrm{DM}$ patients, sitagliptin was reported to have effects after a 6-week treatment [23] and 12-week treatment [24]; gemigliptin was reported to have effects after a 4 -week treatment [25]. There are no reports on DPP4 inhibitors' long-term effects on apo-B48 and no reports on teneligliptin pre- and post-meal apo-B48. Therefore, the effects of teneligliptin on blood glucose and lipids before and after 
a meal were examined before treatment and after a 6-month treatment.

\section{Materials and Methods}

\section{Study design}

This study is an open-label prospective trial conducted in a diabetes-specific clinic in Japan. The present study was carried out in accordance with the study protocol, the Helsinki Declaration of 1964 and later versions and "Ethical Guidelines for Clinical Studies" by the Health, Labor and Welfare Ministry. Before participating in the study, written information was provided to all patients, each of whom provided written consent. The ethics committee at the Diabetes and Lifestyle Center, Tomonaga Clinic approved the study.

\section{Study participants}

Participants met all of the following inclusion criteria and none of the following exclusion criteria. Inclusion criteria were: 1) Type 2 diabetes with hemoglobin $\mathrm{A} 1 \mathrm{c}(\mathrm{HbA} 1 \mathrm{c}) \geq$ $6.5 \%$; 2 ) Twenty years of age; 3 ) No history of changing antidiabetic drugs or antihyperlipidemic agents for 6 months; and 4) Blood glucose levels were poorly controlled by only diet/exercise therapy or diet/exercise and treatment with antidiabetic drugs. Exclusion criteria were: 1) Past history of hypersensitivity to DPP4 inhibitors; 2) Severe ketosis, diabetic coma, precoma, or type 1 diabetes; 3 ) Severe infection or perioperative severe injury; 4) Pregnancy or having childbearing potential; 5) Severe renal dysfunction, dialysis, or end-stage renal disease (ESRD); 6) Hepatic dysfunction; and 7) Inappropriateness for study participation as determined by physicians.

\section{Methods}

In the target patients, treatment with teneligliptin started and biomarkers were measured pre- and post-meal. It was conducted immediately before the first administration and on the day after the 6-month treatment. The meal had $536 \mathrm{kcal}$; protein, $25.6 \mathrm{~g}$; lipids, $13.6 \mathrm{~g}$; carbohydrates, $75.4 \mathrm{~g}$; and salt content, $3.0 \mathrm{~g}$. There were meat and potatoes (Nikujaga), boiled hijiki seaweed and soybeans, boiled mainspring and $150 \mathrm{~g}$ of white rice. During the test, blood glucose levels and insulin levels were measured at 0,60 , and $120 \mathrm{~min}$; and levels of apoB-48, total cholesterol (TC), LDL-C, low-density lipoprotein-free cholesterol (LDL-FC), high-density lipoprotein cholesterol (HDL-C), and TGs were measured at 0 and $120 \mathrm{~min}$. In addition, $\mathrm{HbA} 1 \mathrm{c}$, body weight, and body mass index (BMI) were measured once every month for 6 months. Blood glucose was measured by the glucose oxidase method (amperometric determination of hydrogen peroxide). TC, LCL-C, LDL-FC and TG were measured by the enzymatic method. ApoB-48 was measured using a Human ApoB-48 ELISA kit (FUJIFILM Wako
Shibayagi Co., Gunma, Japan) according to manufacturer's instructions.

\section{Evaluation}

Total area under the curve (tAUC) was the total area above zero, and the incremental area under the curve (iAUC) was positive area above the baseline. The primary endpoint was the change in tAUC of apoB-48 6 months after the start of teneligliptin administration. Secondary endpoints included: 1) Change in blood glucose, insulin, TC, LDL-C, LDL-FC, HDL-C, and TG measured by tAUC and iAUC 6 months after starting teneligliptin; 2) Change in apoB-48 iAUC 6 months after starting teneligliptin; 3) Change in apoB-48, TC, LDL$\mathrm{C}$, LDL-FC, HDL-C, and TG measured by fasting and $2 \mathrm{~h}$ after a meal 6 months after starting teneligliptin; 4) Change in blood glucose and insulin measured by fasting, $1 \mathrm{~h}$ and $2 \mathrm{~h}$ after a meal 6 months after starting teneligliptin; and 5) HbAlc, body weight, BMI, homeostasis model assessment of insulin resistance (HOMA-R), and homeostasis model assessment of $\beta$-cell (HOMA- $\beta$ ) 6 months after the start of teneligliptin. When calculating HOMA-R and HOMA- $\beta$, blood glucose levels of $216 \mathrm{mg} / \mathrm{dL}$ and higher were excluded to ensure accuracy [26]. In addition, we did exploratory analysis as follows: the factors affecting the reduction effect of apoB-48; the changes in TG tAUC and apoB-48 tAUC by dividing the group into those with high baseline TG tAUC and those with low baseline TG tAUC; the changes in TG tAUC and apoB48 tAUC in cases with fasting TG of $150 \mathrm{mg} / \mathrm{dL}$ or higher; the changes in HDL-C tAUC by dividing the group into those with high baseline HDL-C tAUC and those with low baseline HDL-C tAUC.

\section{Statistical analysis}

The data were analyzed using $\mathrm{R}$ version 3.5.2 (R Foundation for Statistical Computing, Vienna, Austria (https://www.Rproject.org/)). With regard to the efficacy, a paired $t$-test or Wilcoxon signed-rank test was used to evaluate the changes in various parameters from baseline at each follow-up point. Comparisons did not take multiplicity into account. The Wilcoxon rank-sum test was used to evaluate the difference between the two groups. For analysis of factors that affect the reduction effect of apoB-48, multiple regression analysis was performed using the amount of change in apoB-48 tAUC as the objective variable, and age, sex, duration of disease, concurrent use of statins, apoB- 48 tAUC at the start, $\mathrm{HbA} 1 \mathrm{c}$ at the start, BMI at the start, fasting blood glucose at the start, fasting insulin at the start, and LDL-C at the start as explanatory variables. In the multiple regression analysis, in addition to cases in which all explanatory variables were adopted, a multiple regression analysis was also performed by the stepwise method using the Akaike information criterion as a sensitivity analysis. Significance was set to a two-sided $\mathrm{P}$ value $<0.05$. The results were shown as the number of cases (\%) for the nominal scale and expressed as mean \pm standard deviation (SD) or median 
Table 1. Participants' Demographic and Other Background Information

\begin{tabular}{|c|c|}
\hline $\mathrm{N}$ & 31 \\
\hline Age (years) & $55.2 \pm 7.0$ \\
\hline Gender & Male/female: $27(87.1 \%) / 4(12.9 \%)$ \\
\hline Weight (kg) & $72.3 \pm 11.9$ \\
\hline $\operatorname{BMI}\left(\mathrm{kg} / \mathrm{m}^{2}\right)$ & $25.5 \pm 3.2$ \\
\hline \multicolumn{2}{|l|}{ Diabetic retinopathy } \\
\hline Diabetic retinopathy & $4(12.9 \%)$ \\
\hline Simple retinopathy & $2(6.5 \%)$ \\
\hline Advanced proliferative retinopathy & $2(6.5 \%)$ \\
\hline Biguanide & $7(22.6 \%)$ \\
\hline Thiazolidine & $0(0 \%)$ \\
\hline$\alpha$-glucosidase inhibitors & $2(6.5 \%)$ \\
\hline SGLT-2-inhibitors & $0(0 \%)$ \\
\hline GLP-1-agonist & $0(0 \%)$ \\
\hline Insulin & $0(0 \%)$ \\
\hline \multicolumn{2}{|l|}{ Antidyslipidemic drug } \\
\hline Statin & $12(38.7 \%)$ \\
\hline Ezetimibe & $1(3.2 \%)$ \\
\hline
\end{tabular}

Data are presented as number (\%) or mean \pm SD. HbA1c: hemoglobin A1c; SGLT-2: sodium-glucose linked transporter-2; GLP-1: glucagon-like peptide-1; BMl: body mass index; SD: standard deviation.

(first quartile, third quartile) for continuous variables.

\section{Results}

All of the 31 patients registered were followed up with after the 6-month treatment. Table 1 lists demographic and other background information. Patients were $55.2 \pm 7.0$ years and men in $87.1 \%$ of cases. They had diabetes for $7.3 \pm 4.1$ years, with $\mathrm{HbA} 1 \mathrm{c}$ of $8.26 \pm 1.25 \%$. Statin was concurrently used in $38.7 \%$ of cases. Changes in medication during the 6-month treatment included discontinuation of antidiabetic metformin in one case, and discontinuation of antihyperlipidemic ezetimibe in one case.

ApoB-48 tAUC $(\mu \mathrm{gh} / \mathrm{mL})$ was significantly decreased from 26.4 (17.1, 49.2) before administration to 22.9 (16.5, 35.0) $(\mathrm{P}=0.041)$ after 6-month teneligliptin treatment (Fig. 1). The pre-meal value of apoB-48 showed a significant decrease as well. The post-meal value also tended to decrease. ApoB-48 iAUC $(\mu \mathrm{gh} / \mathrm{mL})$ was $5.0(2.4,10.0)$ before administration of teneligliptin and $6.3(2.7,8.9) 6$ months after administration, showing no significant difference before and after administration of teneligliptin $(\mathrm{P}=0.854)$.

Table 2 shows the results of biomarkers before and after a meal. The absolute values of iAUC in TC, HDL-C, and LDL-C were significantly decreased 6 months after administration of teneligliptin. As for HDL-C, a significant decrease was observed before a meal and in tAUC and 6 months after the first administration of teneligliptin, but no significant change was observed after $120 \mathrm{~min}$. In LDL-FC and TG, no significant changes were observed before and after 6-month treatment with teneligliptin.

TG tAUC $(\mathrm{mg} \cdot \mathrm{h} / \mathrm{dL})$ with the high-baseline TG tAUC group was changed from $331(371.5,305)$ to $404(480,264)$, and their change was $22(166,-77)(\mathrm{P}=0.454)$. Their apoB-48 tAUC was changed from $47.4(60.1,26.7)$ to $34.9(42.7,23)$, and their change was $-7.3(2.4,33.2)(\mathrm{P}=0.073)$. TG tAUC with the lowbaseline TG tAUC group was changed from $186.5(199.3,160)$ to $192.5(226.3,148.8)$, and its change was $19(42.5,-5.5)(\mathrm{P}=$ $0.109)$. Their apoB-48 tAUC was changed from $19(27.1,13.7)$ to $17.3(23.7,14.8)$, and their change was $-2.1(2,-4.3)(\mathrm{P}=0.274)$. The difference between the two groups was not significant for 


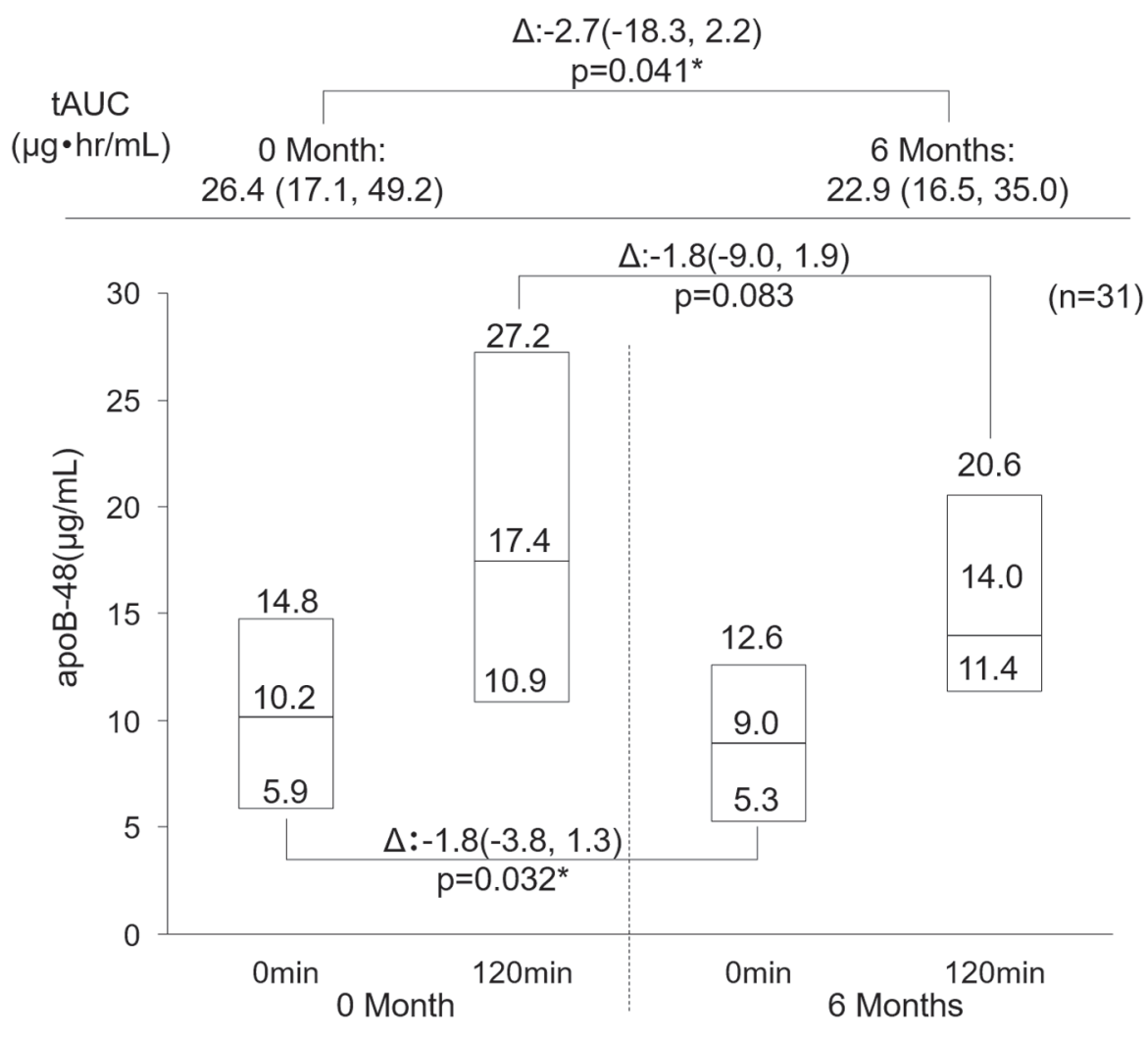

Figure 1. Change in apoB-48. Data are first, second, third quartile. ${ }^{*} \mathrm{P}<0.05$ Wilcoxon signed-rank test. apoB-48: apolipoprotein B-48.

either TG tAUC $(\mathrm{P}=0.830)$ or apoB-48 tAUC $(\mathrm{P}=0.248)$.

TG tAUC in nine cases with fasting TG of $150 \mathrm{mg} / \mathrm{dL}$ or higher was changed from $370(377,333)$ to $460(518,254)$, and their change was $-51(147,-128)(\mathrm{P}=1.000)$. Their apoB48 tAUC was changed from $51.1(61.5,30.5)$ to $40.1(42.8$, 21.7), and their change was $-11.6(-1.3,-34.5)(\mathrm{P}=0.098)$.

HDL-C tAUC $(\mathrm{mg} \cdot \mathrm{h} / \mathrm{dL})$ with the high-baseline HDL-C tAUC group was changed from $124(129.5,115)$ to $118(123.5$, $113)$, and their change was $-9(2,-11)(\mathrm{P}=0.073)$. HDL-C tAUC with the low-baseline HDL-C tAUC group was changed from $85.5(97.3,80.5)$ to $85.5(91.8,77.5)$, and its change was $-3(2.5$, -11.5) $(\mathrm{P}=0.196)$. The difference between the two groups was not significant regarding HDL-C tAUC $(\mathrm{P}=0.812)$.

Blood glucose levels, both before and after $120 \mathrm{~min}$ of meal loading, were significantly reduced after 6-month treatment with teneligliptin (Fig. 2a). Its tAUC ( $\mathrm{mg} \cdot \mathrm{h} / \mathrm{dL})$ was also significantly reduced from $454.5 \pm 83.6$ before administration to $373.9 \pm 83.7$ after 6 months $(\mathrm{P}<0.001)$, and iAUC was significantly reduced from $134.9 \pm 47.0$ to $96.4 \pm 45.7(\mathrm{P}<$ $0.001)$. On the other hand, there was no significant change in insulin level before and after 6 months of meal loading (Fig. $2 b)$. Its tAUC $(\mu \mathrm{Uh} / \mathrm{mL})$ decreased from $34.5 \pm 20.6$ before administration to $34.1 \pm 19.0$ after 6 months, and no significant change was observed $(\mathrm{P}=0.886)$, and iAUC was significantly reduced from $23.1 \pm 16.5$ to $22.4 \pm 17.9(\mathrm{P}=0.818)$.

HbA1c significantly decreased 1 month after the first administration of teneligliptin, and the effect remained (Fig. 3).
The HOMA-R shows change from $2.2 \pm 1.4$ to $2.1 \pm 1.1$, but it was not significant ( $\mathrm{P}=0.681$; paired $t$-test), whereas the HOMA- $\beta(\%)$ also shows change from $25.4 \pm 17.5$ to $30.8 \pm$ 14.5 and it was not significant but it has improvement tendency $(\mathrm{P}=0.104$; paired $t$-test $)$. Body weight $(\mathrm{kg})$ was slowly changed from $72.3 \pm 11.9$ at the start to $72.2 \pm 11.7,71.5 \pm 10.9,70.4 \pm$ $9.5,70.3 \pm 9.5,71.4 \pm 10.0$, and $70.5 \pm 9.5$, after $1,2,3,4,5$ and 6 months, respectively, from the start of antidiabetic treatment. Changes from baseline to each month were not significant.

In the multiple regression analysis of the factors affecting the tAUC change for apoB-48, a higher tAUC level at the start more likely led to a lower tAUC level after the 6-month treatment. The tAUC level of apoB-48 was more likely to fall in women than in men (Table 3 ). These results were similar for both model 1 and model 2 .

No adverse events with an undeniably causal relationship with the study drug occurred during the study period.

\section{Discussion}

\section{Reproducibility of the results of other apoB-48 studies}

This study demonstrated significant apoB-48 reductions in the level of tAUC, conducted before and after 6-month treatment with a teneligliptin. So far, in patients with type 2 diabetes, 
Table 2. Change in Biomarkers Before and After a Meal $(N=31)$

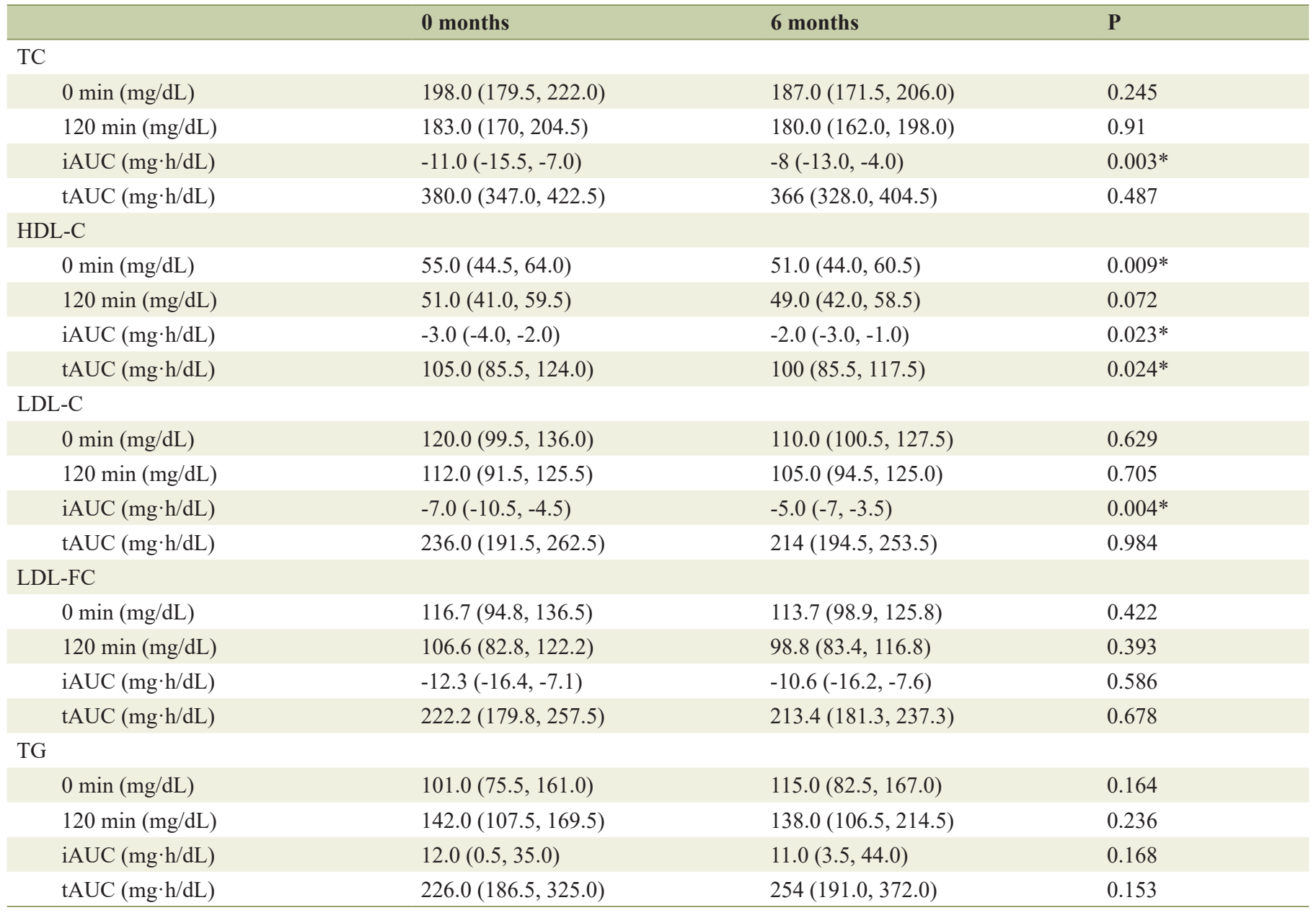

Data are median (first quartile, third quartile). ${ }^{*} \mathrm{P}<0.05$ Wilcoxon signed-rank test. iAUC: incremental area under the curve; tAUC: total area under the curve; TC: total cholesterol; HDL-C: high-density lipoprotein cholesterol; LDL-C: low-density lipoprotein cholesterol; LDL-FC: low-density lipoprotein free cholesterol; TG: triglyceride.

significant postprandial apoB-48 reductions in AUC were reported via lipid or dietary loading after 6 -week or 12 -week treatment with sitagliptin $[23,24]$, and 4-week treatment with gemigliptin [25]. It is difficult to compare these studies by absolute value because the sampling times and contents of the test meals were different. For this reason, we examined the rate of change. Our study showed $10.2 \%$ reduction. Studies with sitagliptin have reported $7.8 \%$ and $21.8 \%$ significant reductions $[23,24]$, and studies with gemigliptin have reported $16.4 \%$ significant reductions [25]. We consider the results appropriate. In our study, apoB-48 iAUC did not change significantly. Ahn et al reported that apoB-48 iAUC was not significantly different compared to placebo in the treatment of gemigliptin. A factor of them might be a decrease in fasting apoB-48 [25].

\section{Mechanism}

Increased expression of DPP4 in the liver is a factor that promotes non-alcoholic fatty liver disease [27], and inhibition of this cycle by a DPP4 inhibitor is one of the mechanisms of lipidlevel improvement. The focus of this study, apoB-48, is synthesized in the small intestine, where DPP-4 activity is suppressed by DPP-4 inhibitor administration, as seen in a study using mice by Waget et al [28]. In addition, glucagon-like peptide 1 (GLP1 ) has been reported to suppress intestinal chylomicron secretion [29]. We suggest that apoB-48 reduction is due to a cycle of inhibiting DPP4, increasing GLP-1 and decreasing chylomicron secretion. Ideta et al showed that teneligliptin increased the expression of phosphorylated adenosine monophosphate (AMP)activated protein kinase protein in mouse livers [30]. Not only inhibition of DPP4 expression in the liver, but also the possibility of attenuating lipogenesis in the liver by controlling the expression of genes involved in lipogenesis are suggested.

\section{Evaluation of lipid-related parameters}

It was also shown that teneligliptin can improve transient hyperlipidemia after a meal. Test values of LDL-C and others 
a

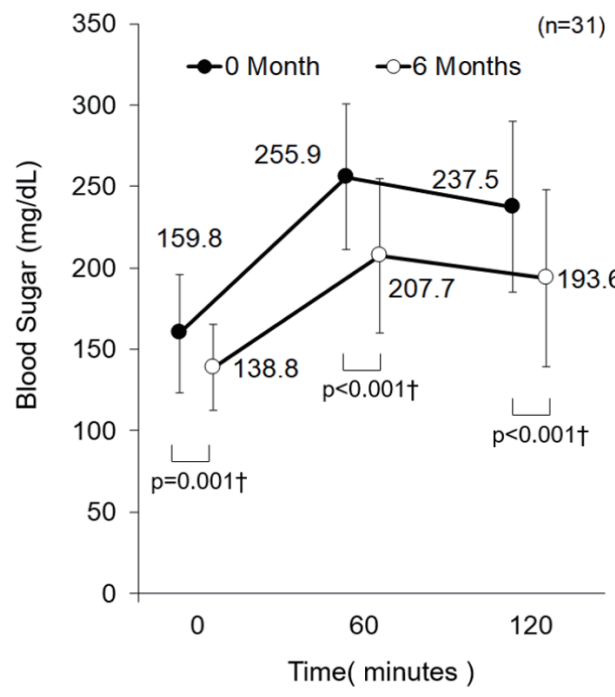

b

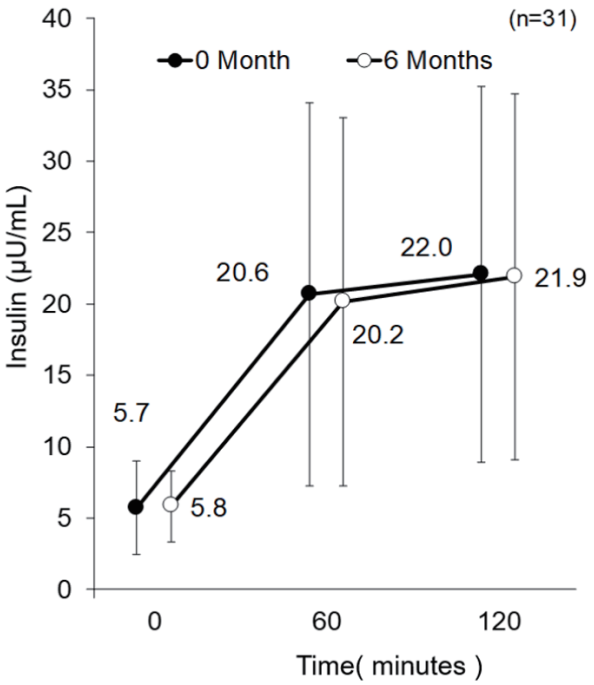

Figure 2. (a) Change in blood sugar. Data are mean $\pm S D$. $\dagger P<0.05$ paired $t$-test. (b) Change in insulin. Data are mean $\pm S D$. No significance for paired $t$-test. SD: standard deviation.

showed an improvement tendency, but no significant change was observed. Nevertheless, it was highly meaningful that a postprandial change in sensitive biomarkers was observed.

The present study found no significant change in tAUC of TC, LDL-C, LDL-FC or TG. Ahn et al [25] also reported no significant decrease in tAUC of TG or TC. On the other hand, Tremblay et al reported a significant decrease in AUC of TG, very low-density lipoprotein cholesterol (VLDL-C) and free fatty acids [23]. These differences of results were indicating that the reproducibility of this finding is difficult to achieve.
The composition of the test meal used in our test and the test meal used in other tests are shown in the supplementary material (Supplementary Material 1, www.jofem.org). In our test meal, carbohydrates are $57 \%$ of energy, lipids are $23 \%$ and protein is $20 \%$. Tremblay et al reported $60 \%$ lipids and a test time of $8 \mathrm{~h}$ [23]. Ahn et al reported 38\% lipids and a test time of $4 \mathrm{~h}$ [25]. The significant decrease in tAUC of TG may be influenced by the difference in test meal composition and the difference in test time. Although HDL-C was significantly reduced, our result suggests that if it is originally low, it does not
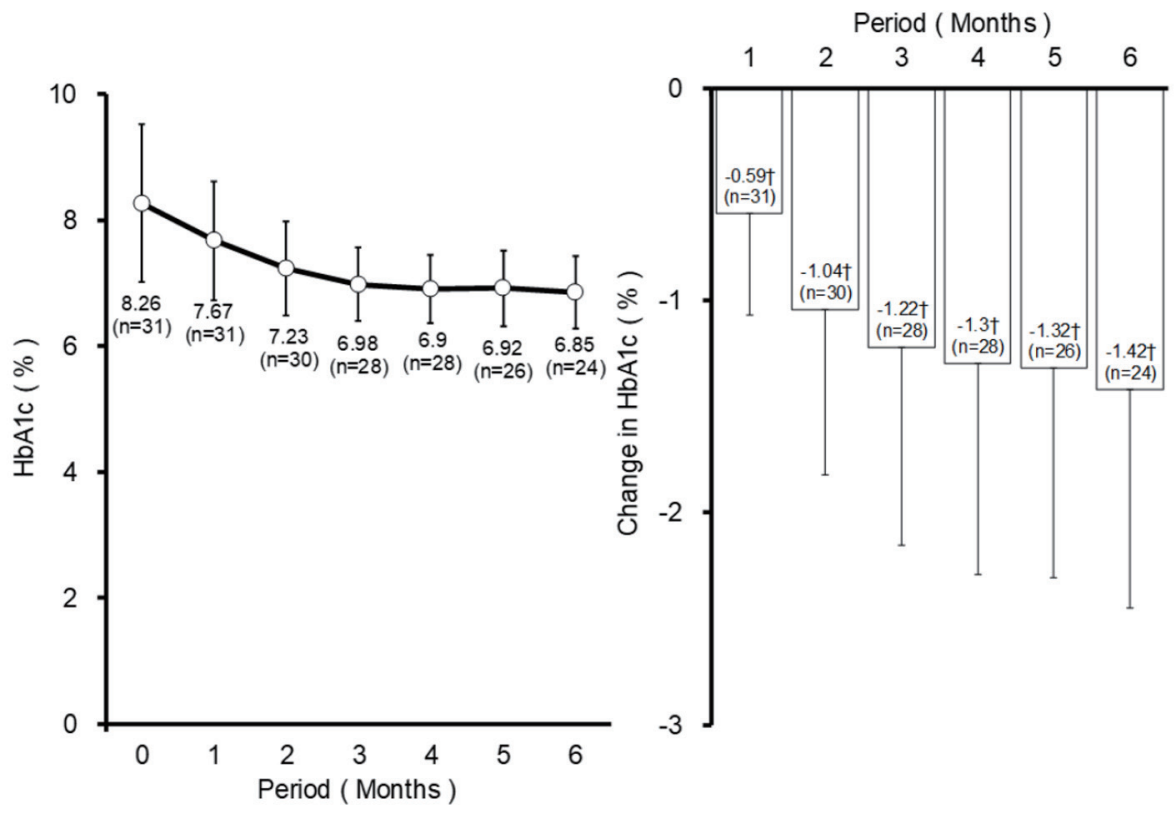

Figure 3. Change in $\mathrm{HbA1c}$. Data are mean $\pm \mathrm{SD}$. $\nmid \mathrm{P}<0.05$ paired $t$-test. SD: standard deviation; HbA1c: hemoglobin $\mathrm{A} 1 \mathrm{c}$. 
Table 3. Factors Affecting the tAUC Change for ApoB-48 $(N=31)$

\begin{tabular}{|c|c|c|c|c|c|c|c|c|}
\hline \multirow[b]{2}{*}{ Item } & \multicolumn{4}{|c|}{ Model 1} & \multicolumn{4}{|c|}{ Model 2} \\
\hline & $\begin{array}{l}\text { Standard partial } \\
\text { regression } \\
\text { coefficient }\end{array}$ & $\begin{array}{l}\text { Partial } \\
\text { regression } \\
\text { coefficient }\end{array}$ & $\begin{array}{l}\text { Standard } \\
\text { error }\end{array}$ & $\mathbf{P}$ & $\begin{array}{l}\text { Standard partial } \\
\text { regression } \\
\text { coefficient }\end{array}$ & $\begin{array}{l}\text { Partial } \\
\text { regression } \\
\text { coefficient }\end{array}$ & $\begin{array}{l}\text { Standard } \\
\text { error }\end{array}$ & $\mathbf{P}$ \\
\hline Age & 0.047 & 0.010 & 0.021 & 0.633 & & & & \\
\hline Gender (male) & 0.195 & 0.900 & 0.377 & $0.027 *$ & 0.196 & 0.902 & 0.307 & $0.007 *$ \\
\hline Duration of disease & -0.116 & -0.044 & 0.033 & 0.203 & & & & \\
\hline ApoB-48 (AUC) & -0.959 & -0.594 & 0.045 & $<0.001^{*}$ & -0.958 & -0.593 & 0.040 & $<0.001 *$ \\
\hline $\mathrm{HbA1c}$ & -0.017 & -0.021 & 0.167 & 0.900 & & & & \\
\hline BMI & -0.045 & -0.022 & 0.041 & 0.593 & & & & \\
\hline Fasting blood sugar & 0.118 & 0.005 & 0.006 & 0.402 & 0.107 & 0.005 & 0.003 & 0.124 \\
\hline
\end{tabular}

The values of explanatory variables are baseline values. Model 1: The case where all explanatory variables were adopted. Model 2: The case with the stepwise method using the Akaike information criterion as a sensitivity analysis. apoB-48: apolipoprotein B; HbA1c: hemoglobin A1c; BMI: body mass index; LDL-C: low-density lipoprotein cholesterol; AUC: area under the curve; tAUC: total area under the curve. ${ }^{*} \mathrm{P}<0.05$ multiple regression analysis.

fall excessively. HDL-C was reduced, but it was not an adverse event and did not affect safety.

In our study, the absolute values of iAUC in TC, HDL-C, and LDL-C were significantly decreased 6 months after administration of teneligliptin. The reduced variability of these biomarkers means reducing extra stretch in the blood vessels. This may reduce the load on the blood vessels.

The tAUC of apoB-48 was significantly decreased, but the tAUC of TG was not. This result suggests that apoB-48 may not be the major constituent of TG-rich lipoproteins in postprandial plasma in this study. We did an exploratory analysis of the changes in TG tAUC and apoB-48 tAUC by dividing the group into those with high-baseline TG tAUC and those with low-baseline TG tAUC. As a result, no significant intragroup variation was observed between the two groups, and no significant difference was observed in the amount of change in tAUC between the groups. In nine cases with fasting TG of $150 \mathrm{mg} /$ $\mathrm{dL}$ or higher, the tAUC of TG did not change significantly, but the tAUC of apoB-48 tended to decrease. Although lipoprotein lipase (LPL) metabolizes apoB-48 chylomicrons after a meal, it is possible that teneligliptin suppressed the action of LPL. Homma et al reported that there was no significant change in LPL in the 12-week trial of teneligliptin [31], but there was no report of LPL changes before and after a meal. The results of our study suggested that continuous use of teneligliptin may suppress short-term postprandial LPL. Also, in the report of Tremblay et al [23], the blood concentrations of TG and apoB48 peaked at about $6 \mathrm{~h}$, and no significant difference was observed between the placebo and sitagliptin up to $2 \mathrm{~h}$. In our study of teneligliptin, it is possible that apoB-48 had an effect in the early phase, and that it might have taken a little longer before the difference in TG appeared.

To date, some reports have suggested many improvements in lipid markers by DPP4 inhibitors [15-18, 32-36] including teneligliptin [31, 37-39] used in the present study. The time when significant improvement is recognized in each index seems to vary. In addition, the direct effects on vascular endothelium and cardiovascular events have not been examined in this study, but the DPP4 inhibitor can reduce inflammation in perivascular adipose tissues and suppress atherogenesis in mice [40]. Improvements in human flow-mediated dilation levels have also been reported [41]. We believe that the decrease in apoB-48 level by teneligliptin suggests that they can prevent arteriosclerosis and possibly protect the cardiovascular system.

\section{Factors affecting the fluctuation factors of apoB-48}

In this analysis, the higher the apoB-48 tAUC was at the start, the more likely it was to decrease, and the more likely it was to fall in women than in men. We analyzed them by using two models and found that the significant factors were the same. The mean value of apoB-48 tAUC at the start of this study was 40.4 for men versus 33.1 for women; although not significantly different, the values were higher in men (data not shown). In this study, women were 53 to 66 years old (data not shown), probably postmenopausal on the basis of the average menopause age of 50 years in Japanese women. According to Masuda et al [42], generally postmenopausal women have significantly higher apoB-48 than premenopausal women, but in the same report, apoB-48 was higher in men than in postmenopausal women without significant difference. The apoB48 gender values at the start in the present study are found to be similar to the values reported by Masuda et al [42] and so are not unusual. This is a result of multiple regression analysis that takes into account the mutual effects of other variables, including background information. Additionally, the lower- 
ing of apoB-48 by teneligliptin in women is more likely to be independent of the starting value. It is not clear why gender is a factor, but Perez-Durillo et al found higher postprandial plasma levels of DPP4 activity in non-obese women than in non-obese men [43]. In their report, postmenopausal women were excluded, but another report mentioned that DPP4 activity was not significantly different between postmenopausal women and premenopausal women [44]. Since DPP4 activity was higher in women than in men in this study, it is possible that apoB-48 reduction due to DPP4 inhibition in women was likely to occur in the small intestine. However, regarding the blood glucose control effect of DPP4 inhibitors, no difference between the sexes has been reported, and further reports are awaited to elucidate the causes of marked differences in sex in the small intestine.

\section{Glycemic indexes and body weight}

The blood glucose was significantly decreased in fasting individuals, and after 60 and 120 min of meal loading. In addition, no significant change was observed in the insulin level in fasting individuals, and after $60 \mathrm{~min}$ and $120 \mathrm{~min}$ of meal loading. A similar tendency was observed in the report [25] about the inhibitory effect of gemigliptin on the meal challenge response, but no significant difference in blood glucose level occurred between $30 \mathrm{~min}$ and $2 \mathrm{~h}$ postprandially. The number of gemigliptin cases was 10 , and our teneligliptin study was 31 . It is considered that a significant result was reflected by securing the number of cases. Although there was no significant change in the insulin level, HOMA- $\beta$ showed improvement tendency, indicating that insulin secretion improved, which was also true for gemigliptin.

Regarding $\mathrm{HbA} 1 \mathrm{c}$, a significant decrease was observed 1 month after the start, and the effect was maintained even after 6 months. In addition, there was no significant change in body weight over 6 months, and it is considered that the drug does not cause weight gain. The results were similar to findings in various other reports so far $[17,45]$.

In addition, there were no adverse events with an undeniable causal relationship to the treatment and the drug is safe to use.

\section{Study limitations}

Since this study had no control group, it cannot be compared to studies with other drugs. We did not research the levels of other apolipoproteins (apoA-1, apoA-2, apoB-100, apoE).

\section{Conclusions}

After 6-month treatment with teneligliptin, a statistically significant decrease in apoB-48 was observed during fasting and after a meal. In addition, the high level of apoB-48 at the beginning and female gender are factors that impact the significant teneligliptin-induced decrease in apoB-48. These results suggest that DPP4 inhibitors may be beneficial for treating arteriosclerotic lesions in diabetic patients.

\section{Supplementary Material}

Suppl 1. Composition Ratio of Test Meal in Each Test.

\section{Acknowledgments}

We would like to express our sincere gratitude to Shido Inc. for conducting the data collection and analyses.

\section{Financial Disclosure}

The study was funded by Diabetes and Lifestyle Study Society.

\section{Conflict of Interest}

None to declare.

\section{Informed Consent}

All patients provided informed written consent prior to participation in the study.

\section{Author Contributions}

OT conceived and designed the experiments, enrolled patients, and wrote the first draft of the manuscript; OT, MK, RT, and YH analyzed the data; OT, MK, RT and YH contributed to the writing of the manuscript; OT, MK, RT, and YH agreed with the manuscript's results and conclusions. All authors have read and confirmed that they meet International Committee of Medical Journal Editors (ICMJE) criteria for authorship.

\section{Data Availability}

The datasets used and/or analyzed during the current study are available from the corresponding author on reasonable request.

\section{References}

1. Beckman JA, Creager MA, Libby P. Diabetes and atherosclerosis: epidemiology, pathophysiology, and management. JAMA. 2002;287(19):2570-2581.

2. Fox CS, Golden SH, Anderson C, Bray GA, Burke LE, de Boer IH, Deedwania P, et al. Update on prevention of cardiovascular disease in adults with type 2 diabetes mellitus in light of recent evidence: a scientific statement from the American Heart Association and the American Diabetes 
Association. Circulation. 2015;132(8):691-718.

3. American Diabetes A. 9. Cardiovascular disease and risk management: standards of medical care in diabetes-2018. Diabetes Care. 2018;41(Suppl 1):S86-S104.

4. Emerging Risk Factors C, Sarwar N, Gao P, Seshasai SR, Gobin R, Kaptoge S, Di Angelantonio E, et al. Diabetes mellitus, fasting blood glucose concentration, and risk of vascular disease: a collaborative meta-analysis of 102 prospective studies. Lancet. 2010;375(9733):2215-2222.

5. Seshasai SRK, Kaptoge S, Thompson A, Di Angelantonio E, Gao P, Sarwar N, Whincup PH, et al. Diabetes mellitus, fasting glucose, and risk of cause-specific death. N Engl J Med. 2011;364(9):829-841.

6. Matsuzaki M, Kita T, Mabuchi H, Matsuzawa Y, Nakaya N, Oikawa S, Saito Y, et al. Large scale cohort study of the relationship between serum cholesterol concentration and coronary events with low-dose simvastatin therapy in Japanese patients with hypercholesterolemia. Circ J. 2002;66(12):1087-1095.

7. Sone H, Katagiri A, Ishibashi S, Abe R, Saito Y, Murase T, Yamashita H, et al. Effects of lifestyle modifications on patients with type 2 diabetes: the Japan Diabetes Complications Study (JDCS) study design, baseline analysis and three year-interim report. Horm Metab Res. 2002;34(9):509-515.

8. Sone H, Ito H, Ohashi Y, Akanuma Y, Yamada N, Japan Diabetes Complication Study G. Obesity and type 2 diabetes in Japanese patients. Lancet. 2003;361(9351):85.

9. Huang ES, Meigs JB, Singer DE. The effect of interventions to prevent cardiovascular disease in patients with type 2 diabetes mellitus. Am J Med. 2001;111(8):633-642.

10. Collins R, Armitage J, Parish S, Sleigh P, Peto R, Heart Protection Study Collaborative G. MRC/BHF Heart Protection Study of cholesterol-lowering with simvastatin in 5963 people with diabetes: a randomised placebo-controlled trial. Lancet. 2003;361(9374):2005-2016.

11. Colhoun HM, Betteridge DJ, Durrington PN, Hitman GA, Neil HA, Livingstone SJ, Thomason MJ, et al. Primary prevention of cardiovascular disease with atorvastatin in type 2 diabetes in the Collaborative Atorvastatin Diabetes Study (CARDS): multicentre randomised placebo-controlled trial. Lancet. 2004;364(9435):685-696.

12. Kim MK, Chae YN, Ahn GJ, Shin CY, Choi SH, Yang EK, Sohn YS, et al. Prevention and treatment effect of evogliptin on hepatic steatosis in high-fat-fed animal models. Arch Pharm Res. 2017;40(2):268-281.

13. Nath S, Ghosh SK, Choudhury Y. A murine model of type 2 diabetes mellitus developed using a combination of high fat diet and multiple low doses of streptozotocin treatment mimics the metabolic characteristics of type 2 diabetes mellitus in humans. J Pharmacol Toxicol Methods. 2017;84:20-30.

14. Fukuda-Tsuru S, Kakimoto T, Utsumi H, Kiuchi S, Ishii S. The novel dipeptidyl peptidase-4 inhibitor teneligliptin prevents high-fat diet-induced obesity accompanied with increased energy expenditure in mice. Eur J Pharmacol. 2014;723:207-215.

15. Monami M, Lamanna C, Desideri CM, Mannucci E. DPP-4 inhibitors and lipids: systematic review and meta- analysis. Adv Ther. 2012;29(1):14-25.

16. Ishikawa M, Takai M, Maeda H, Kanamori A, Kubota A, Amemiya $\mathrm{H}$, Iizuka $\mathrm{T}$, et al. Factors predicting therapeutic efficacy of combination treatment with sitagliptin and insulin in type 2 diabetic patients: the ASSIST-K study. J Clin Med Res. 2015;7(8):607-612.

17. Sakura H, Hashimoto N, Sasamoto K, Ohashi H, Hasumi S, Ujihara N, Kasahara T, et al. Effect of sitagliptin on blood glucose control in patients with type 2 diabetes mellitus who are treatment naive or poorly responsive to existing antidiabetic drugs: the JAMP study. BMC Endocr Disord. 2016;16(1):70.

18. Masuda D, Kobayashi T, Sairyou M, Hanada H, Ohama T, Koseki M, Nishida M, et al. Effects of a dipeptidyl peptidase 4 inhibitor sitagliptin on glycemic control and lipoprotein metabolism in patients with type 2 diabetes mellitus (GLORIA Trial). J Atheroscler Thromb. 2018;25(6):512-520.

19. Nakajima K, Nagamine T, Fujita MQ, Ai M, Tanaka A, Schaefer E. Apolipoprotein B-48: a unique marker of chylomicron metabolism. Adv Clin Chem. 2014;64:117177.

20. Karpe F. Postprandial lipoprotein metabolism and atherosclerosis. J Intern Med. 1999;246(4):341-355.

21. Parks EJ. Recent findings in the study of postprandial lipemia. Curr Atheroscler Rep. 2001;3(6):462-470.

22. Mori Y, Yamamoto T, Tokuno A, Hirano T. Apolipoprotein $\mathrm{B} 48$ increment after test meal A increases small dense low-density lipoprotein cholesterol independently of triglyceride. J Japan Diab Soc. 2010;53(8):593-600 (in Japanese).

23. Tremblay AJ, Lamarche B, Deacon CF, Weisnagel SJ, Couture P. Effect of sitagliptin therapy on postprandial lipoprotein levels in patients with type 2 diabetes. Diabetes Obes Metab. 2011;13(4):366-373.

24. Kojima Y, Kaga H, Hayashi S, Kitazawa T, Iimura Y, Ohno M, Yoshitsugu M, et al. Comparison between sitagliptin and nateglinide on postprandial lipid levels: The STANDARD study. World J Diabetes. 2013;4(1):8-13.

25. Ahn CH, Kim EK, Min SH, Oh TJ, Cho YM. Effects of gemigliptin, a dipeptidyl peptidase-4 inhibitor, on lipid metabolism and endotoxemia after a high-fat meal in patients with type 2 diabetes. Diabetes Obes Metab. 2017;19(3):457-462.

26. Turner RC, Holman RR, Matthews D, Hockaday TD, Peto $\mathrm{J}$. Insulin deficiency and insulin resistance interaction in diabetes: estimation of their relative contribution by feedback analysis from basal plasma insulin and glucose concentrations. Metabolism. 1979;28(11):1086-1096.

27. Baumeier C, Schluter L, Saussenthaler S, Laeger T, Rodiger M, Alaze SA, Fritsche L, et al. Elevated hepatic DPP4 activity promotes insulin resistance and non-alcoholic fatty liver disease. Mol Metab. 2017;6(10):1254-1263.

28. Waget A, Cabou C, Masseboeuf M, Cattan P, Armanet M, Karaca M, Castel J, et al. Physiological and pharmacological mechanisms through which the DPP-4 inhibitor sitagliptin regulates glycemia in mice. Endocrinology. 2011;152(8):3018-3029.

29. Qin X, Shen H, Liu M, Yang Q, Zheng S, Sabo M, 
D'Alessio DA, et al. GLP-1 reduces intestinal lymph flow, triglyceride absorption, and apolipoprotein production in rats. Am J Physiol Gastrointest Liver Physiol. 2005;288(5):G943-949.

30. Ideta T, Shirakami Y, Miyazaki T, Kochi T, Sakai H, Moriwaki H, Shimizu M. The dipeptidyl peptidase-4 inhibitor teneligliptin attenuates hepatic lipogenesis via AMPK activation in non-alcoholic fatty liver disease model mice. Int J Mol Sci. 2015;16(12):29207-29218.

31. Homma K, Yoshizawa J, Shiina Y, Ozawa H, Igarashi M, Matsuoka T, Sasaki J, et al. A dipeptidyl peptidase-4 inhibitor, teneligliptin, decreases plasma triglyceride-rich lipoprotein remnants in diabetic patients with chronic kidney disease undergoing hemodialysis. Drugs R D. 2017;17(3):397-402.

32. Kaku K. Effects of anagliptin on serum lipids in Japanese patients with type 2 diabetes - a pooled analysis of long-term therapy with anagliptin. Jpn Pharmacol Ther. 2012;40:771-784.

33. Chiba Y, Yamakawa T, Tsuchiya H, Oba M, Suzuki D, Danno H, Takatsuka Y, et al. Effect of anagliptin on glycemic and lipid profile in patients with type 2 diabetes mellitus. J Clin Med Res. 2018;10(8):648-656.

34. Kakuda H, Kobayashi J, Kakuda M, Yamakawa J, Takekoshi N. The effect of anagliptin treatment on glucose metabolism and lipid metabolism, and oxidative stress in fasting and postprandial states using a test meal in Japanese men with type 2 diabetes. Endocrine. 2015;48(3):1005-1009.

35. Yano $\mathrm{W}$, Inoue $\mathrm{N}$, Ito $\mathrm{S}$, Itou $\mathrm{T}$, Yasumura $\mathrm{M}$, Yoshinaka Y, Hagita S, et al. Mechanism of lipid-lowering action of the dipeptidyl peptidase-4 inhibitor, anagliptin, in lowdensity lipoprotein receptor-deficient mice. J Diabetes Investig. 2017;8(2):155-160.

36. Morimoto T, Sakuma I, Sakuma M, Tokushige A, Natsuaki M, Asahi T, Shimabukuro M, et al. Randomized evaluation of anagliptin vs sitagliptin on low-density lipoproteiN cholesterol in diabetes (REASON) Trial: a 52-week, open-label, randomized clinical trial. Sci Rep. 2019;9(1):8537.

37. Shah K. Teneligliptin in Early Diabetic Kidney Disease: An Observation in Asian Indian Patients with Type 2 Dia- betes Mellitus in Real-Life Scenario. J Clin Diagn Res. 2017;11(6):OC22-OC25.

38. Kim Y, Kang ES, Jang HC, Kim DJ, Oh T, Kim ES, Kim NH, et al. Teneligliptin versus sitagliptin in Korean patients with type 2 diabetes inadequately controlled with metformin and glimepiride: A randomized, double-blind, non-inferiority trial. Diabetes Obes Metab. 2019;21(3):631-639.

39. Kusunoki M, Sato D, Nakamura T, Oshida Y, Tsutsui H, Natsume Y, Tsutsumi K, et al. DPP-4 Inhibitor Teneligliptin Improves Insulin Resistance and Serum Lipid Profile in Japanese Patients with Type 2 Diabetes. Drug Res (Stuttg). 2015;65(10):532-534.

40. Salim HM, Fukuda D, Higashikuni Y, Tanaka K, Hirata Y, Yagi S, Soeki T, et al. Teneligliptin, a dipeptidyl peptidase-4 inhibitor, attenuated pro-inflammatory phenotype of perivascular adipose tissue and inhibited atherogenesis in normoglycemic apolipoprotein-E-deficient mice. Vascul Pharmacol. 2017;96-98:19-25.

41. Noda Y, Miyoshi T, Oe H, Ohno Y, Nakamura K, Toh $\mathrm{N}$, Kohno K, et al. Alogliptin ameliorates postprandial lipemia and postprandial endothelial dysfunction in nondiabetic subjects: a preliminary report. Cardiovasc Diabetol. 2013;12:8.

42. Masuda D, Nishida M, Arai T, Hanada H, Yoshida H, Yamauchi-Takihara K, Moriyama $\mathrm{T}$, et al. Reference interval for the apolipoprotein B-48 concentration in healthy Japanese individuals. J Atheroscler Thromb. 2014;21(6):618-627.

43. Perez-Durillo FT, Segarra AB, Villarejo AB, RamirezSanchez M, Prieto I. Influence of diet and gender on plasma DPP4 Activity and GLP-1 in patients with metabolic syndrome: an experimental pilot study. Molecules. 2018;23(7).

44. Siciliano PO, Godoy-Matos AF, Braga L, Denise Pires Carvalho J, Correa J. DPP4 activity is related to body weight and central fat in postmenopausal women. Diabetes Metab Syndr. 2019;13(5):3031-3034.

45. Takeda H, Sasai N, Ito S, Obana M, Takuma T, Takai M, Kaneshige $\mathrm{H}$, et al. Efficacy and safety of alogliptin in patients with type 2 diabetes: analysis of the ATTAK-J study. J Clin Med Res. 2016;8(2):130-140. 